\title{
Participated Strategies for Small Towns Regeneration. The Case of Oliena (Nu) Historic Centre
}

\author{
Laura Daglio, Giuseppe Boi and Roberto Podda
}

\begin{abstract}
Dealing with the issue of depopulation and abandonment of villages and small towns in Italy and Europe is amongst the goals of the economic and social policies aimed at investigating and experimenting new strategies for the regeneration and reactivation of urban space. An extensive literature collects researches aimed at analysing the problem, exploring diverse management and design approaches, alternative measures to stop the phenomenon and innovative legislative incentives and economic tools. This paper has the aim of reporting an ongoing research experience concerning participated solutions aimed at developing new possible models for the regeneration of Oliena's historic centre, in Sardinia.
\end{abstract}

Keywords Participatory design $\cdot$ Depopulation $\cdot$ Historic villages $\cdot$ Regeneration strategies

\section{Background}

Forestalling population decline and the abandonment of small towns in Italy and in Europe is the goal of economic and social policies aimed at investigating strategies for the re-qualification and reactivation of urban space. An extensive literature endorses researches intended at exploring management, typological and technological approaches (Castagneto and Fiore 2013), new possible programs (Di Figlia 2016) and innovative legislative and economic tools (Flora and Crucianelli 2013; Maietti 2008).

\section{Daglio $(\varangle)$}

Architecture, Built Environment and Construction Engineering-ABC Department, Politecnico di Milano, Milan, Italy

e-mail: laura.daglio@polimi.it

G. Boi

Milan, Italy

R. Podda

Department of Architecture, Xi' an Jiaotong - Liverpool University, Suzohu, China

(C) The Author(s) 2020 
The recent exhibition at the 16 Venice Biennial Italian Pavilion, 'Arcipelago Italia', curated by Mario Cucinella showcased the issue of the territories which are 'spatially and temporally distant from the large urban areas', ${ }^{1}$ especially characterised by a lack of services and infrastructures. Inner areas, fragile territories, abandoned landscapes, shrinking cities (Oswalt et al. 2006) the diverse definitions present in the literature and in the media highlight the urgent problem of these areas, which possess an inestimable cultural heritage both tangible and intangible but no economic wealth. Albeit not a novel question, it has been harshened by the consequences of the economic crisis as well as the rapid ageing of the population, increasing the differences and the unbalances between regions of the same country.

A rich literature focuses on this topic presenting an evolution in the approaches and in the models of possible actions, which can be classified and recognised according to some selected criteria such as initiative and permanence. Bottom-up rather than topdown projects are featured, involving participatory design as a potential approach, and strategic or tactical solutions are experimented, including the time variable in the proposal and realisation of activities, events, new constructions and renovations. However, all these projects have to deal with the task of reinterpreting the built environment and of defining the appropriate solutions to intervene on the existing heritage. In fact, together with the problem of geographical isolation, these ancient settlements suffer not only from a physical decay due to the lack of maintenance and the abandonment, but also from a functional obsolescence. Conceived to host the activities of societies and rural or industrial economies, that do not exist anymore, the built environment requires an upgrading and renovation to respond to the changed demands of the potential new inhabitants. Thus, a dialogue with the authorities and the rules regulating the modes and approaches of renovation of historic heritage are required, also considering that the introduction of new regulations and constraints to limit and define these interventions often caused the freezing of the heritage, limiting the transformation and introducing complex and long-lasting procedures.

In spite of these common features, these areas are extremely different from the point of view of the geographic, economic, social, cultural and historical background. In addition, a considerable number were also abandoned due to the occurrence of natural disasters, now raising the issue of the opportunity for the renovation, in terms of resources to be employed.

The ongoing debate and recent case studies disclose the increasing application of participatory processes to develop measures for the redevelopment projects, whilst solutions involving the top-down creation of a new building or activity, also requiring a significant investment, are almost disappearing.

The lively emergence of participatory design initiatives is aimed at determining the new demand (Sennet 2012), developing new strategies with co-design activities to create and share new meanings and goals and frequently employ tactical urbanism methodologies (Lydon and Garcia 2011) to anticipate possible scenarios, to raise awareness and a sense of belonging in the inhabitants.

${ }^{1} \mathrm{Cf}$. the exhibition and project site at http://www.arcipelagoitalia.it/en/home (accessed May 5th 2019). 
This paper has the aim of reporting a recent research experience concerning shared solutions aimed at enquiring new possible models for the reactivation of Oliena's historic centre, in Barbagia. The research, still ongoing, is patronised by the Municipality and the GAL Barbagia; these institutions endorsed the activities and offered economical and operative support, believing in the participatory methodology as a means to trigger change in mentality and built environment.

\section{Problems and Potentials of the Oliena Region}

The characters of the depopulation phenomenon in Oliena are slightly different from the recurring elements to determine the abandonment. In fact, the small town (approximately 7000 inhabitants) is in the centre of Sardinia, thus far from the developed touristic coastal areas, in the mountain zone of Supramonte, with a lack of infrastructures for transportation — as mainly all the Mediterranean Island towns - but adjacent to the province capital of Nuoro. The majority of the population is in fact employed in the public sector or in the administration, in agriculture and in the breeding industry, and they are not affected by major economic issues either by massive migration processes to the coast or to other national or international destinations.

However, the historic centre of Oliena is characterised by an ongoing abandonment. Since the seventies and the eighties, inhabitants moved towards the outer expansion areas, where they built low-density single-family housing settlements that better responded to contemporary lifestyles. Accordingly, the transformation of the town centre into a periphery is a consequence of the inadequacy of the historic urban fabric and of the roads and of the functional obsolescence of the existing buildings. In addition, the zoning ordinance transformed the town centre into a conservation area (Zone A), without producing specific guidelines for renovation, thus freezing the old town and hindering the potential for transformation. Currently, this large heritage, which extends for more than 27 ha, is undergoing a significant physical decline, revealed by the increasing number of condemned buildings and ruins (Fig. 1).

The historical documentary value of the ancient centre relies in the morphological, typological and technological characteristics of the urban fabric, since the presence of artistic landmarks and monuments is limited.

The ancient settlement, in between the Monte Corrasi and the fertile valley of the Cedrino River, is organised in closed courtyards belonging to a large family, where all the main past social and productive activities took place. The so-called Cortes represent the legacy of a rural society based on family clans, currently disappeared, intrinsically tied to their region (Fig. 2). This relationship of belonging and identity is still very strong in the present population, as the belief that the ancient centre cannot be adapted to contemporary requirements of use without major significant intervention of replacement and reconstruction and is therefore doomed to an inescapable abandonment.

For this reason, the research team realised that any proposal to trigger the physical transformation of the centre solution should tackle with the transformation of 


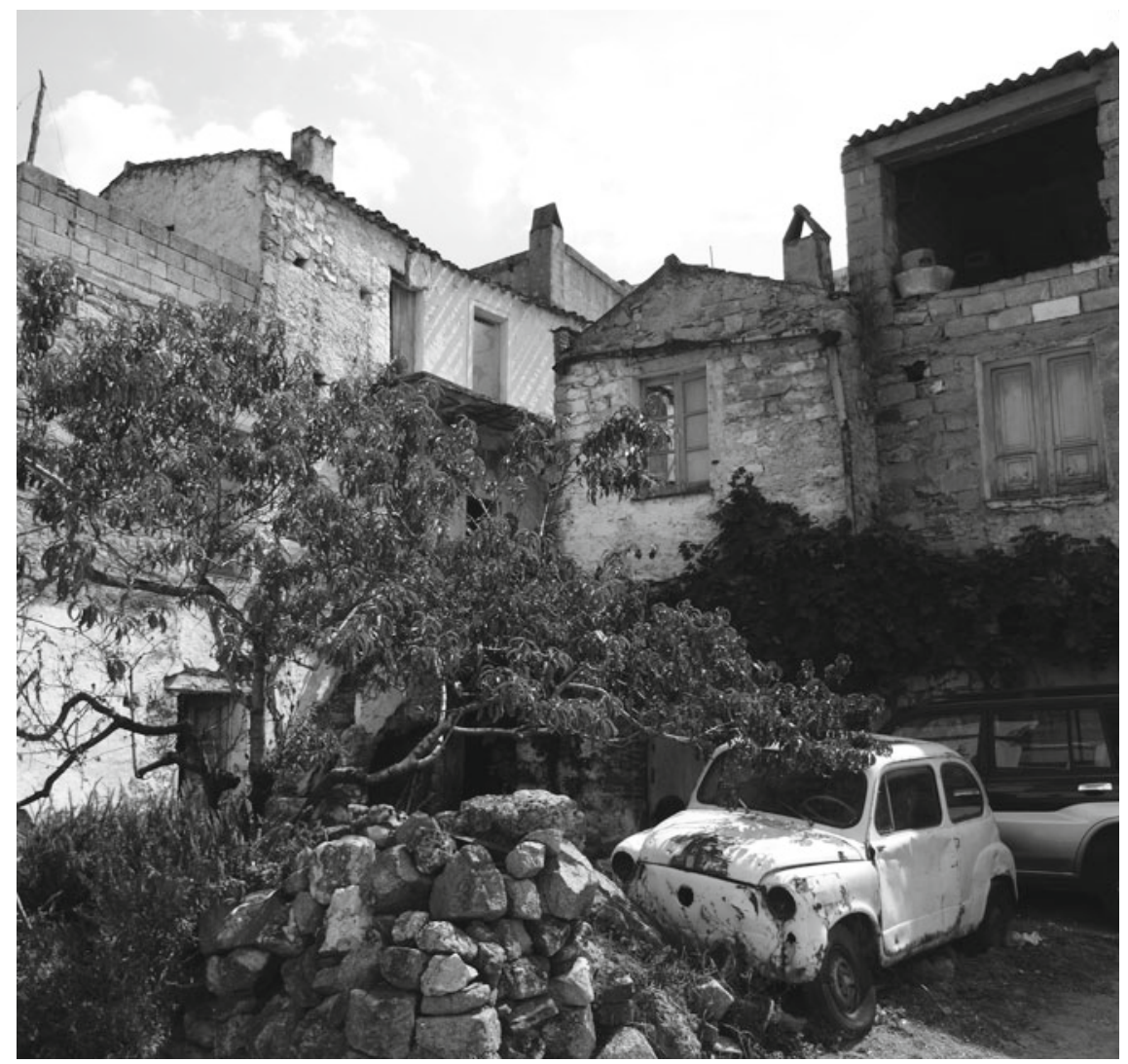

Fig. 1 The number of condemned building is progressively increasing (source photo by the Authors)

its perception by the people who inhabit it, according to the European Landscape Convention (European Council 2000), and therefore with their involvement and participation.

This was the origin of the research activity, dealing with the definition of possible scenarios of intervention, emerging from the local identity and the social and cultural peculiarities of the place.

Accordingly, the research path encompasses, on the one hand, an analytical phase dedicated to understanding the place, its problems and potentials, as well as a review of the scientific literature on the topic of regeneration models and strategies on a national and international scale. The goal of these steps is to define possible strategies, approaches and solutions for the renovation of the historic centre.

On the other hand, participatory initiatives were developed as a tool for deepening the investigation of the landscape, understanding the demands, sharing the results of the design solutions explored and encouraging an increasing awareness of the value of the abandoned places and of a spontaneous re-appropriation of the space. 


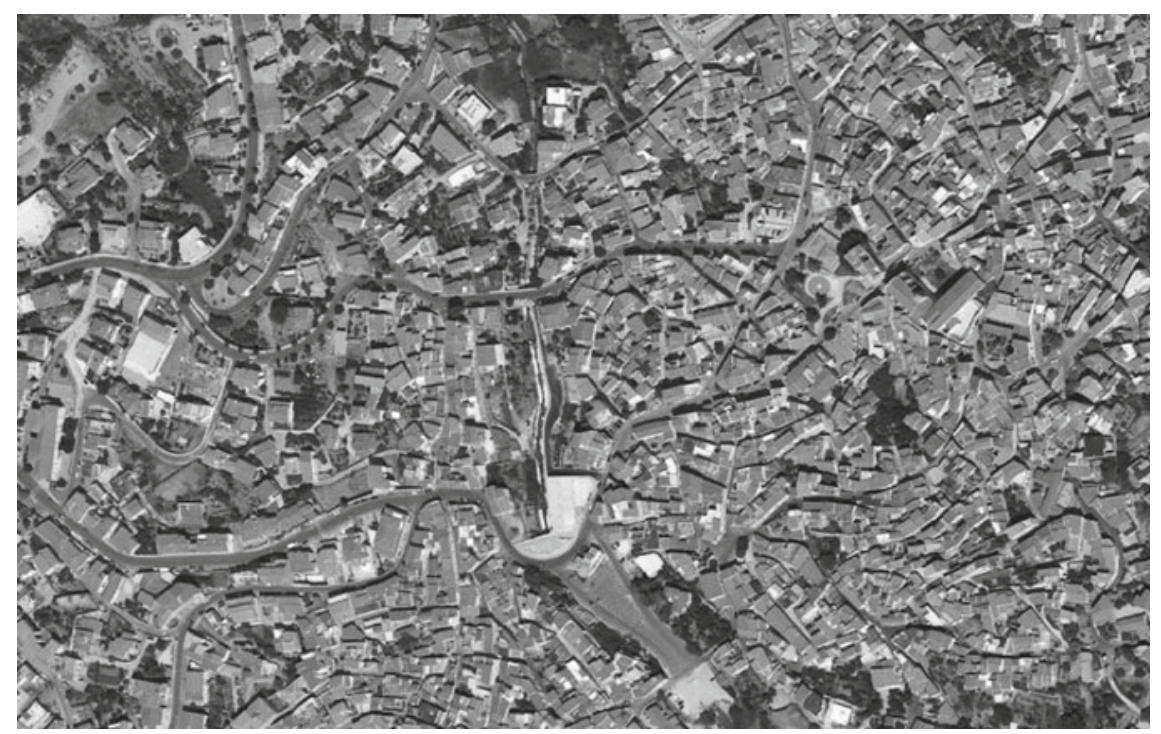

Fig. 2 Aerial view showing the urban fabric characterised by the building grouped around semipublic courtyards (Cortes) (source Sardegna Geoportale)

The analysis of the Oliena region revealed potentials and problems: potentials related to the lush and fertile agricultural territory characterised by the high quality of its food products, wine and oil in particular; to the beauty of the natural mountain landscape with its limestone karst highlands, excavated by the underground waters to create caves and sinkholes; to the rich ancient and diverse culture still present in the handicraft and witnessed by the many archaeological sites, menhirs and Palaeolithic villages. However, the investigation also highlighted that the main issues hindering the exploitation of these aspects to trigger economic development rely on the lack of networks and of systemic strategies to put together and connect the different small fragmented activities into a bigger collective operator with increased investment capacity in resources, infrastructures and marketing. Simultaneously, a similar networking of the existing touristic resources (natural, historical and experiential) could call visitors from the seaside areas or activate new all-year-round modes of holidaying in the region. In addition, the ownership of the historic centre buildings is extremely fragmented and therefore requires the development of any initiative to be shared and agreed with the many owners.

Once again the analysis highlighted the need to raise awareness in the population to generate a new perception of their homeland in order to start change as well as the requisite of finding solutions to gather consensus on a wide basis.

These initial results pointed to the elaboration and enhancement of the specific approaches for the possible design proposals and to the organisation of diverse participated events, each to stimulate a different reaction in the local population. 


\section{Development of the Methodological Approach}

The research defined two different intertwined paths for the development of the activities to stimulate the involvement of the local population: on the one hand, the exploration of the capacity of the existing urban texture to accommodate different new facilities emerging from the features of the social, economic and geographic context. This testing was applied on some typical selected plots of the historic centres with different locations and slightly different morphologies. Following the analytical phase, new possible functions were identified in relation to the potentials relying in the beauty of the landscape (tourism and sport facilities), in the excellence of the wine and food products (exhibitions and food processing), in the handicraft (exhibitions and enterprises) and in the proximity to the 'blue zone' ${ }^{2}$ (homes for the elderly and health). The design entailed not only the urban and architectural renovation of the existing buildings but also the design of the process, the definition of the different possible stages of the transformation and reactivation, the involved stakeholders in each phase and the possible funding to assess the concrete feasibility of the proposal. Moreover, all the projects portray a multiscalar, multidimensional feature investigating the proposal as part of a larger network of diverse activities and places spread on the local territory as well as linked to wider structures through ICT technologies, in order to promote synergies and to create systems as unavoidable approach for the reactivation of the area. Finally, also the issue of defining the appropriate approach towards the refurbishment and renovation of the historic heritage was examined, experimenting architectural solutions that, whilst ensuring the recognition of the existing heritage, revisited and tested its adaptability to the changing needs of the contemporary living through a 'grafting' practice.

On the other hand, public events were organised with the twofold aim of presenting the results of the design exploration through exhibitions and of discussing the potentials, methods, feasibility and opportunity within workshops and seminars open to the citizens. The different initiatives were organised over the years to deepen the involvement and the exploration in conjunction with the annual 'Cortes Apertas' fair in September, which for over 20 years has summoned a large public of visitors from all Sardinia and national and international tourists. Hence, the fair displaying the local products was an opportunity also to present the results of the research and to host the debate and raise the awareness in the inhabitants towards the models and the scenarios for the re-appropriation of the historic centre. Three workshops were organised and conceived with an increasing engagement of the citizens.

The first was intended as a round table ${ }^{3}$ involving scholars from around Italy to discuss the issue of the regeneration of historic centres. Internationally renowned

\footnotetext{
${ }^{2}$ Barbagia and Ogliastra regions in Sardinia are included in the so-called Blue Zones: regions of the world where people live much longer than average because of the social geographical food and lifestyle features.

${ }^{3}$ The seminar was held in Oliena on 10 September 2016 and was attended by A. Sanna, C. Atzeni (University of Cagliari), E. D’Alfonso, L. Daglio, P. Mei, R. Podda (Politecnico di Milano), S. Garattini (M. Negri Institute), G. Onni, P. Pittaluga and F. Spanedda (Università di Sassari).
} 


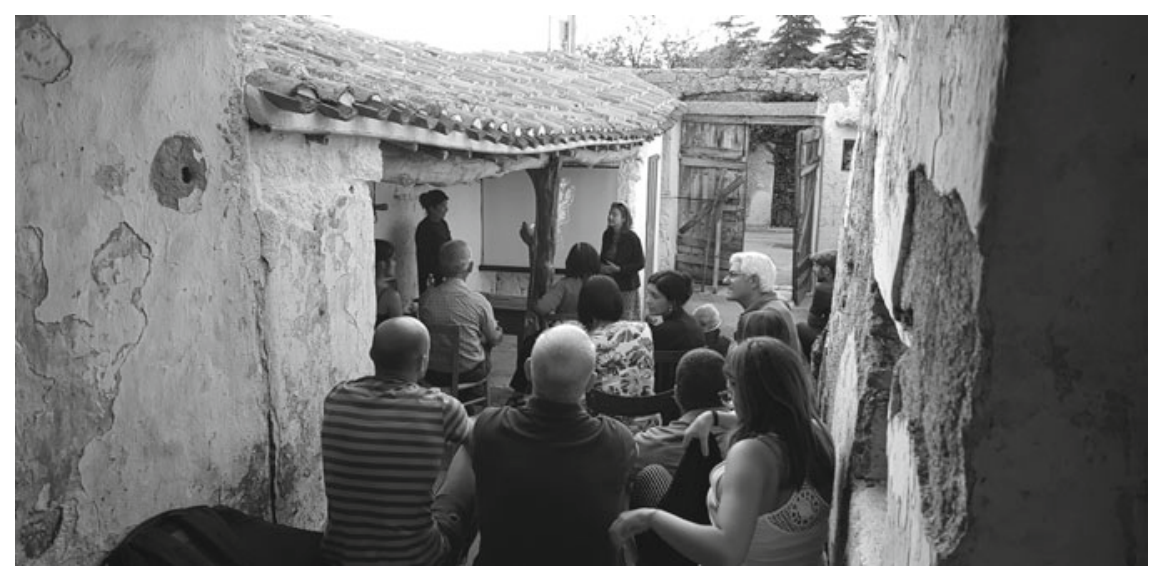

Fig. 3 The 2018 edition of the participatory workshop took place in one of the ancient courtyards (source photo by the Authors)

scholars and experts from different fields and disciplines were invited in the weeklong workshops ${ }^{4}$ organised in the two following consecutive years to present their work and projects with the aim of collecting case studies and experiences on similar contexts and to deepen the knowledge of the characters and potentials of the region.

During the last workshop, ${ }^{5}$ a site-specific installation inside one of the ancient Cortes (courtyards) (Fig. 3) was designed and constructed as one of the fair's installations to highlight the physical and cultural heritage of the village (Fig. 4). Simultaneously, local producers and farmers and local associations related to sports (speleology, climbing and cycling), culture (tourist guide associations and local experts) and leisure were consulted during the workshops in order to understand their needs, criticalities and potentials. In particular, visits and activities were organised together with these stakeholders in order to share their experiences and directly comprehend their everyday life. Such immersive practices by the researchers team having a different culture and background also allowed for a different interpretation of the context, the emergence of a different perspective to see and analyse the local culture and landscape and to disclose original potentials.

\footnotetext{
${ }^{4}$ The 2017 edition was open to the Master Degree students in Architecture at Politecnico di Milano and Architecture and Building Engineering and Architecture and Ph.D. students of the University of Cagliari, Sassari, seat of Alghero, the Politecnico di Milano, the University of Alcalá de Henares, the University of Lisbon and the Tianjin University.

${ }^{5}$ In the last workshop, the School of Design and the School of Architecture Urban Planning Construction Engineering of Politecnico di Milano, together with the Tianjin University, were involved.
} 


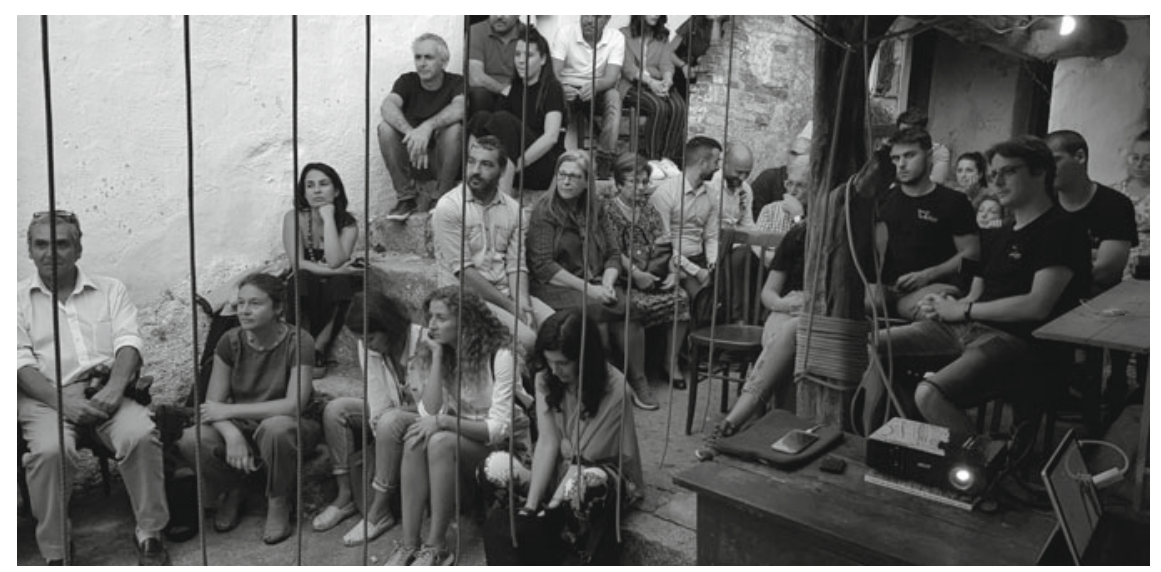

Fig. 4 The visits to the site-specific installation in 2018 (source photo by the Authors)

\section{Conclusion}

The success of the yearly workshops in terms of public participation to the meetings and to the initiatives testifies the achievement of the goal of raising awareness in the inhabitants. Ordinary people followed and participated in the seminars, attended to the lectures and discussed with the young teams of researchers that involved (master course, just graduated and Ph.D. students) the proposals and their specific needs, expectations and the geographical and economic constraints of the region.

The Municipality, and the counsellors albeit changed after the elections, promote and patronise the events organised by the research team, also participating in the debates during the workshops and seizing the opportunity to start a direct dialogue with the citizens.

Moreover, after the first two workshops, the owners of the historic centre's buildings did realise the potentials of networking and of starting bottom-up actions and gathered in a new association called Oliena Centro, with the aim of strengthening their initiatives and sharing problems and opportunities. This has also created the basis for a crowdfunding to start concrete actions.

Finally, the workshops became also a meeting place for the participants to trigger a dialogue amongst the too often separated operators, to know each other better and to foster new synergies and collaborations and to start working together for the common good.

The lessons learned from the case study of Oliena are important in terms of methodology enhancement. In particular, the participatory tools were differently declined to include: discussions/debates with the citizens aimed at analysing their demands and expectations as well as their perception of their home land and culture; the creation of a two-way dialogue and direct exchange between Municipality and citizens; disruptive cognitive reactions generated on the one hand by the supply of 
external expertise to the inhabitants and on the other hand by the provision of knowhow and intangible heritage experiences to the research team. The latter appeared as the main trigger towards innovation and change, raising awareness and the commitment to the village centre regeneration in the locals and suggesting original paths to define possible feasible strategies.

\section{References}

Castagneto, F., \& Fiore, V. (Eds.). (2013). Recupero, valorizzazione, manutenzione nei centri storici: un tavolo di confronto interdisciplinare. Siracusa: Lettera Ventidue.

Consiglio d'Europa. (2000). Convenzione Europea del Paesaggio. [Online] Available at: http://www.convenzioneeuropeapaesaggio.beniculturali.it/uploads/2010_10_12_11_22_02. pdf. Accessed May 10, 2019.

Di Figlia, L. (2016). Turnaround: Abandoned villages, from discarded elements of modern Italian society to possible resources. International Planning Studies, 21(3), 278-297.

Flora, N., \& Crucianelli, E. (Eds.). (2013). I borghi dell'uomo: strategie e progetti di ri-attivazione. Siracusa: Lettera ventidue.

Lydon, M., \& Garcia, A. (2011). Tactical urbanism: Short-term action for long-term change. Washington DC: Island Press.

Maietti, F. (Ed.). (2008). Centri storici minori: progetti di recupero e restauro del tessuto urbano. Maggioli: Santarcangelo di Romagna.

Oswalt, P., Beyer, E., Hagemann, A., \& Rieniets, T. (2006). Atlas of shrinking cities. Ostfildern: Hatje Cantz Pub.

Sennet, R. (2012). Together. The rituals, pleasures and politics of cooperation. Yale: Yale University Press.

Open Access This chapter is licensed under the terms of the Creative Commons Attribution 4.0 International License (http://creativecommons.org/licenses/by/4.0/), which permits use, sharing, adaptation, distribution and reproduction in any medium or format, as long as you give appropriate credit to the original author(s) and the source, provide a link to the Creative Commons license and indicate if changes were made.

The images or other third party material in this chapter are included in the chapter's Creative Commons license, unless indicated otherwise in a credit line to the material. If material is not included in the chapter's Creative Commons license and your intended use is not permitted by statutory regulation or exceeds the permitted use, you will need to obtain permission directly from the copyright holder.

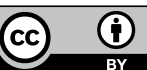

